\section{Kidney \\ Blood Pressure Research}

\title{
Clinicopathological Features to Predict Progression of IgA Nephropathy with Mild Proteinuria
}

\author{
Ding Chen ${ }^{\mathrm{a}}$ Jian Liu ${ }^{\mathrm{a}}$ Shuwei Duan ${ }^{\mathrm{a}}$ Pu Chen ${ }^{\mathrm{a}} \quad$ Li Tang $^{\mathrm{a}} \quad$ Li Zhang $^{\mathrm{a}} \quad$ Zhe Feng $^{\mathrm{a}}$ \\ Guangyan $\mathrm{Cai}^{\mathrm{a}} \quad$ Jie $\mathrm{Wu}^{\mathrm{a}} \quad$ Xiangmei Chen ${ }^{\mathrm{a}}$ \\ aDepartment of Nephrology, Chinese People's Liberation Army (PLA) General Hospital, Chinese PLA \\ Institute of Nephrology, State Key Laboratory of Kidney Diseases, National Clinical Research Center for \\ Kidney Diseases, Beijing Key Laboratory of Kidney Diseases, Beijing, China
}

\author{
Key Words \\ IgA nephropathy $\bullet$ Mild proteinuria $\cdot$ Clinicopathological $\bullet$ Progression
}

\begin{abstract}
Background/Aims: In the past, little attention has been paid to patients with IgA nephropathy (IgAN) who had minimal proteinuria upon the onset. The aim of this study was to analyze the clinicopathological features and the prognostic factors in patients with IgA nephropathy. Methods: Data of patients that had their first renal biopsy in our hospital and were diagnosed with primary IgAN with proteinuria <1 g/d from January 1995 to December 2014 were retrospectively examined. Clinical records of the clinicopathological features, renal function, and proteinuria were collected and investigated. The factors affecting the renal function and proteinuria were analyzed by Cox regression. The predictive efficiencies of clinical and pathological models were evaluated by Harrell concordance index (C-index). Results: A total of 506 patients with IgA nephropathy were included in this study. (1) Baseline proteinuria greater than $0.5 \mathrm{~g} / \mathrm{d}$ was positively associated with Oxford M, S, and T lesions. eGFR less than $90 \mathrm{~mL} / \mathrm{min} / 1.73 \mathrm{~m}^{2}$ were positively associated with Oxford T. (2) In the follow-up with a median of 50 months, 82 patients (16.2\%) achieved complete clinical remission (CCR), whereas 54 patients $(10.6 \%)$ showed an increase in creatinine by more than $50 \%$ (not progressing to endstage renal disease). The cumulative proportion of creatinine increased $>50 \%$, and the values obtained by life-table analysis in 10,15, and 20 years were $15 \%, 21 \%$, and $22 \%$, respectively. Significant differences were found in baseline age, proteinuria, and Oxford $T$ between the group of creatinine increase $>50 \%$ and the CCR group. (4) Multivariate COX regression showed that baseline age and proteinuria $>0.5 \mathrm{~g} / \mathrm{d}$ were independent risk factors of adverse outcome. C-index suggested that the clinical model was more effective than the pathological
\end{abstract}

D. Chen, J. Liu and X. Chen contributed equally to this work.

\begin{tabular}{ll}
\hline Jie Wu & Department of Nephrology, Chinese People's Liberation Army (PLA) General Hospital \\
and Xiangmei Chen & Fuxing Road No.28, Haidian District; Beijing, 100853 (China) \\
& Tel. +8618210128683, +8601066935462 E-Mail wujie301@126.com, xmchen301@126.com
\end{tabular}




\section{Kidney Blood Pressure Research}

models in predicting endpoint events. (5) Effect of the mean value during the follow-up on adverse endpoint events: Multivariate COX regression found that the mean proteinuria during follow-up was an independent influencing factor for the increase of creatinine by more than $50 \%$. Conclusion: (1) Proteinuria $>0.5 \mathrm{~g} / \mathrm{d}$ and eGFR $<90 \mathrm{~mL} / \mathrm{min} / 1.73 \mathrm{~m}^{2}$ may predict more severe pathological changes; (2) With the increase in age and baseline proteinuria, the risks of adverse endpoint events would increase significantly; (3) Pathology could roughly predict the adverse endpoint events but is less efficient than the clinical indicators; (4) Data during follow-up suggested that the patients should regularly test their renal function and proactively control their proteinuria.

(C) 2018 The Author(s)

Published by S. Karger AG, Basel

\section{Introduction}

IgAN is currently considered a chronic progressive disease, and more than $50 \%$ of the cases progress despite the active treatment applied [1]. Among them, approximately $20 \%-40 \%$ of the patients progress to end-stage renal disease (ESRD) [2,3]. Pathological changes, including mesangial hypercellularity (M), endocapillary proliferation (E), segmental sclerosis (S), tubular atrophy/interstitial fibrosis (T), and crescent (C), are considered independent risk factors for progression of IgAN to ERSD [4-7]. However, these results are obtained mainly in IgAN patients with urinary protein $>1 \mathrm{~g} / \mathrm{d}$. In the past, IgAN patients with proteinuria $<1$ $\mathrm{g} / \mathrm{d}$ were believed to have slowly progressing conditions and good prognosis [8]. Studies in Asia revealed that $7 \%-24 \%$ of the IgAN patients with mild proteinuria, normal renal function, and normal blood pressure progressed to renal dysfunction [9-11]. Therefore, it is important to understand the prognosis of these patients and determine the factors that lead to disease progression. This study analyzed the clinical and pathological features of IgAN patients with urinary protein level $<1 \mathrm{~g} / \mathrm{d}$ and eGFR $\geq 60 \mathrm{~mL} / \mathrm{min} / 1.73 \mathrm{~m}^{2}$, as well as the influencing factors for adverse renal outcomes, to provide the basis for the clinical identification of the patients with a tendency to disease progression.

\section{Materials and Methods}

\section{Subjects}

Patients that had their first renal biopsy and had been diagnosed with IgAN during their hospitalization in PLA General Hospital (Beijing, China) from January 1995 to December 2014 were included in this study. The following inclusion criteria were used: (1) 18 years of age or older, male or female; (2) 24-h urinary protein quantification at least twice before renal biopsy and urinary protein level <1 g/d; (3) eGFR $\geq 60$ $\mathrm{mL} / \mathrm{min} / 1.73 \mathrm{~m}^{2}$ before the renal biopsy; (4) Number of glomeruli $\geq 8$ in PAS staining of renal biopsies; (5) Not treated with corticosteroids and/or immunosuppressive agents before the renal biopsy; (6) Followed up for at least 12 months after the renal biopsy. The exclusion criteria were as follows: (1) IgAN secondary to Henoch-Schönlein purpura (HSP), rheumatoid arthritis, hepatitis B virus-associated glomerulonephritis and cirrhosis; (2) combined with other kidney diseases, such as diabetic nephropathy, interstitial nephritis, etc.; (3) combined with systemic diseases that affect the pathological manifestations and prognosis of IgAN, such as diabetes, autoimmune diseases, active tuberculosis, malignant tumor, and severe infection.

\section{Methods}

All included medical records were reviewed. The clinical and pathological data before the renal biopsy, age at the renal biopsy, sex, and latency from the onset of the disease to time of the renal biopsy were collected. The following clinical indicators were used in the evaluation: clinical diagnosis, presence of macroscopic hematuria, presence of hypertension, blood pressure, and treatment before the renal biopsy [12]; clinical indices before the diagnosis included urine routine, 24-hour urine protein, serum creatinine, serum albumin, total cholesterol, and triglyceride. eGFR was calculated using the CKD-EPI formula for Asians [13]. Pathology was evaluated according the Oxford classification [14]. 


\section{Kidney \\ Blood Pressure Research}

Table 1. Baseline characteristics

\begin{tabular}{lcc}
\hline Characteristics & Number & Mean \pm SD \\
\hline Age & 34.71 & \pm 9.46 \\
Male (\%) & 276 & $(54.5)$ \\
Hypertension (\%) & 166 & $(32.8)$ \\
Systolic pressure (mmHg) & 123.52 & \pm 15.75 \\
Diastolic pressure (mmHg) & 79.68 & \pm 11.83 \\
Mean arterial pressure (mmHg) & 94.3 & \pm 12.4 \\
Proteinuria (g/d) & 0.56 & \pm 0.26 \\
Proteinuria <0.5g/d & 214 & $(42.3)$ \\
Serum creatinine (umol/l) & 77.99 & \pm 18.50 \\
CKD stage I/ II & 362 & $/ 144$ \\
eGFR (mL/min/1.73 m ${ }^{2}$ ) & 102.12 & \pm 19.82 \\
Albumin (G/L) & 41.42 & \pm 3.63 \\
Cholesterol (mmol/L) & 4.39 & \pm 0.89 \\
Triglyceride (mmol/L) & 1.58 & \pm 1.05 \\
ACEI/ARB (\%) & 404 & $(79.8)$ \\
Steroids (\%) & 69 & $(13.6)$ \\
Oxford Classification & & \\
M0 & 351 & $(69.4 \%)$ \\
M1 & 155 & $(30.6 \%)$ \\
E0 & 480 & $(94.9 \%)$ \\
E1 & 26 & $(5.1 \%)$ \\
S0 & 154 & $(30.4 \%)$ \\
S1 & 352 & $(69.6 \%)$ \\
T0 & 423 & $(83.6 \%)$ \\
T1 & 75 & $(14.8 \%)$ \\
T2 & 8 & $(1.6 \%)$ \\
C0 & 413 & $(81.6 \%)$ \\
C1 & 93 & $(18.4 \%)$ \\
\hline
\end{tabular}

For presentation and definition of the data after the renal biopsy, time-averaged values were used to represent the blood pressure and proteinuria during the follow-up, namely, time-averaged mean arterial pressure (TA-MAP), and time-averaged urinary protein (TA-P). All time-dependent parameters were calculated as time-averaged values based on a trapezoidal rule [15]. The area under the curve formed by the repeated measurements at every visit was divided by the elapsed time up to the end of the follow-up period, yielding a single time-averaged value for a time-dependent parameter. In addition, TA-MAP was similarly calculated.

The events that were observed after the renal biopsy were as follows: (1) Complete clinical remission (CCR): 24-hour urinary protein stabilized at less than $0.2 \mathrm{~g} / \mathrm{d}$, absence of blood, normal renal function, and normal blood pressure in at least three urinary routines; (2) Serum creatinine increased by more than $50 \%$ from baseline; (3) ESRD: eGFR $<15 \mathrm{~mL} / \mathrm{min} / 1.73 \mathrm{~m}^{2}$ or receiving long-term dialysis or kidney transplantation. The cumulative proportion of endpoint events in 10, 15, and 20 years was calculated by life-table analysis.

\section{Results}

\section{Baseline clinical indices}

A total of 506 patients with IgAN met the inclusion criteria during the period 19952014 period and were enrolled in the study (Table 1). Males accounted for $54.5 \%$ of the subjects (276 cases).; Average age at renal biopsy was $34.7 \pm 9.46$ years; Before renal biopsy, 165 patients $(32.6 \%)$ had a history of gross hematuria, 60 patients $(11.8 \%)$ had simple proteinuria, and $31(5.1 \%)$ patients had simple hematuria; 167 patients $(33.0 \%)$ had hypertension, and systolic pressure was $(123.52 \pm 15.75) \mathrm{mmHg}$, diastolic pressure was $(79.68 \pm 11.83) \mathrm{mmHg}$, and mean arterial pressure was $(94.3 \pm 12.4) \mathrm{mmHg}$. Average proteinuria was $0.56 \pm 0.26 \mathrm{~g} / \mathrm{d}$ among these patients. The results of other tests were serum creatinine $77.99 \pm 18.5 \mathrm{umol} / \mathrm{L}$, eGFR $102.1 \pm 19.82 \mathrm{~mL} / \mathrm{min} / 1.73 \mathrm{~m}^{2}$, albumin $41.42 \pm 3.63$ $\mathrm{g} / \mathrm{L}$, total cholesterol $4.39 \pm 0.89 \mathrm{mmol} / \mathrm{L}$, triglyceride $1.58 \pm 1.05 \mathrm{mmol} / \mathrm{L}, 362$ patients $(71.5 \%)$ were at CKD stage I. 69 patients $(13.6 \%)$ started on steroids therapy. 


\section{Kidney Blood Pressure Research}

\section{Pathology}

Oxford classification: For mesangial cell proliferation (M), 155 cases (30.6\%) were classified as M1; for endocapillary proliferation (E), 26 cases (5.1\%) were classified as E1; for segmental glomerulosclerosis/glomerular adhesions (S), 352 cases (69.6\%) were classified as S1; and for tubular atrophy/interstitial fibrosis (T), 76 cases (14.8\%) were classified as $\mathrm{T} 1$ and eight cases were classified as T2. In assessment of glomerular crescents, 413 of the cases $(81.6 \%)$ showed no crescents (C0), 93 of the cases $(18.4 \%)$ showed crescents of $\mathrm{C} 1$, and none of the cases showed crescent in over $25 \%$ of glomeruli (C2).

\section{Correlation between baseline clinical indices and pathology}

Proteinuria greater than $0.5 \mathrm{~g} / \mathrm{d}$ was positively correlated with Oxford $\mathrm{M}, \mathrm{S}$, and T lesions, whereas stage 2 CKD was positively correlated with T lesions (see Table 2).

\section{Outcomes}

No patients progressed to ESRD. 54 patients with creatinine increased by greater than $50 \%$. The cumulative proportion of creatinine increased $>50 \%$ in 10,15 , and 20 years were $15 \%, 21 \%$ and $22 \%$, respectively (see Table 3 ). Based on the endpoint proteinuria and creatinine during follow-up, all patients were divided into three groups: Complete clinical remission (group1), including 82 patients with proteinuria less than $0.2 \mathrm{~g}$ and no increase in creatinine; group 2 , including 370 patients with proteinuria greater than $0.2 \mathrm{~g}$ and creatinine increased by less than $50 \%$; and group 3 , including 54 patients with creatinine increased by greater than $50 \%$.

Baseline Clinicopathological Differences between Patients in the CCR Group and group with creatinine increased $>50 \%$

As for baseline clinicopathological data, compared with creatinine increased $>50 \%$ group, the CCR group had smaller age, lower baseline proteinuria, slighter T lesions in Oxford classification; the difference was statistically significant $(P<0.05)$ as shown in Table 4. Neither steroids nor ACEI/ARB was statistically significant between CCR group and creatinine increased $>50 \%$ group $(P>0.05)$.

Table 2. Correlation between baseline clinical indices and Oxford classification. ${ }^{* *} \mathrm{P}<0.01$

\begin{tabular}{lcccccc}
\hline Baseline clinical indices & & $\mathrm{M}$ & $\mathrm{E}$ & $\mathrm{S}$ & $\mathrm{T}$ & $\mathrm{C}$ \\
\hline \multirow{2}{*}{ Proteinuria $>0.5 \mathrm{~g} / \mathrm{d}$} & correlation coefficient & $0.118^{* *}$ & 0.018 & $0.121^{* *}$ & $0.131^{* *}$ & 0.086 \\
& $\mathrm{P}$ & 0.008 & 0.685 & 0.007 & 0.003 & 0.053 \\
\multirow{2}{*}{ CKD II } & correlation coefficient & -0.020 & -0.067 & -0.011 & $0.206^{* *}$ & -0.017 \\
& $\mathrm{P}$ & 0.653 & 0.130 & 0.802 & 0.000 & 0.710 \\
\hline
\end{tabular}

Table 3. The cumulative proportion of creatinine increased $>50 \%$ in 10,15 , and 20 years by life-table analysis

\begin{tabular}{lccc}
\hline & 10 years & 15 years & 20 years \\
\hline Creatinine increased $>50 \%$ & $15 \%$ & $21 \%$ & $22 \%$ \\
Complete clinical remission & $23 \%$ & $28 \%$ & $32 \%$ \\
\hline
\end{tabular}




\section{Kidney \\ Blood Pressure Research}

Table 4. Baseline Clinicopathological Differences Between Patients in CCR Group and creatinine increased $>50 \%$ Group

\begin{tabular}{|c|c|c|c|c|c|}
\hline \multirow{2}{*}{$\begin{array}{l}\text { Characteristics } \\
\text { Sex (female/male) }\end{array}$} & \multicolumn{2}{|c|}{$\begin{array}{c}\mathrm{CCR} \\
(\mathrm{n}=82)\end{array}$} & \multicolumn{2}{|c|}{ Creatinine increased $>50 \%(\mathrm{n}=54)$} & \multirow{2}{*}{$\begin{array}{c}\mathrm{P} \\
0.156\end{array}$} \\
\hline & 46 & $/ 36$ & $37 / 17$ & & \\
\hline Age & 32.65 & \pm 9.23 & 35.93 & \pm 10.37 & 0.039 \\
\hline Proteinuria $(g / d)$ & 0.39 & \pm 0.23 & 0.60 & \pm 0.27 & $<0.001$ \\
\hline Systolic pressure $(\mathrm{mmHg})$ & 118.54 & \pm 13.39 & 122.33 & \pm 14.64 & 0.148 \\
\hline Diastolic pressure $(\mathrm{mmHg})$ & 75.06 & \pm 9.53 & 77.86 & \pm 11.69 & 0.094 \\
\hline Mean arterial pressure $(\mathrm{mmHg})$ & 89.55 & \pm 9.97 & 92.68 & \pm 12.03 & 0.092 \\
\hline Serum creatinine (umol/L) & 68.65 & \pm 15.54 & 67.38 & \pm 19.17 & 0.281 \\
\hline $\operatorname{eGFR}\left(\mathrm{mL} / \mathrm{min} / 1.73 \mathrm{~m}^{2}\right)$ & 113.10 & \pm 16.74 & 109.17 & \pm 20.42 & 0.514 \\
\hline Albumin (G/L) & 40.92 & \pm 3.49 & 39.62 & \pm 3.68 & 0.055 \\
\hline Cholesterol (mmol/L) & 4.16 & \pm 0.92 & 4.42 & \pm 0.78 & 0.056 \\
\hline Triglyceride (mmol/L) & 1.44 & \pm 0.82 & 1.44 & \pm 0.85 & 0.981 \\
\hline \multirow{2}{*}{ ACEI/ARB } & Yes & 24 & & 15 & 1 \\
\hline & No & 58 & & 39 & \\
\hline \multirow[t]{2}{*}{ Steroids } & Yes & 11 & & 8 & 0.837 \\
\hline & No & 71 & & 46 & \\
\hline \multicolumn{6}{|l|}{ Oxford classificiation } \\
\hline \multirow[t]{2}{*}{ Oxford M } & M0 & 67 & & 38 & 0.092 \\
\hline & M1 & 15 & & 16 & \\
\hline \multirow[t]{2}{*}{ Oxford E } & E0 & 77 & & 52 & 0.423 \\
\hline & E1 & 5 & & 2 & \\
\hline \multirow[t]{2}{*}{ Oxford S } & so & 33 & & 16 & 0.14 \\
\hline & S1 & 49 & & 38 & \\
\hline \multirow[t]{2}{*}{ Oxford $\mathrm{T}$} & T0 & 79 & & 47 & 0.431 \\
\hline & $\mathrm{T} 1$ & 3 & & 7 & \\
\hline \multirow[t]{2}{*}{ Oxford C } & $\mathrm{C} 0$ & 66 & & 42 & 0.431 \\
\hline & C1 & 16 & & 12 & \\
\hline
\end{tabular}

Risk factors of creatinine increased $>50 \%$ and predictive effect of baseline clinicopathological indicators on patient's outcome

Univariate COX regression [16] indicated that age, baseline proteinuria, Oxford $\mathrm{T}$ were the influencing factors of the adverse endpoint event of creatinine increased $>50 \%$ from baseline. However, multivariate COX regression showed that only age and baseline proteinuria were independent influencing factors of such adverse endpoint event $(P<0.05)$. See Table 5. These results suggested that the baseline pathological indicators might be not as effective in predicting disease progression. By further calculating C-Index, it was found that Oxford classification was less effective than the clinical indicators in predicting the adverse endpoint events for IgAN patients with minor proteinuria (see Table 6).

\section{Correlation Between Adverse Endpoint and Clinical Indicators During Follow-up}

The clinical data during follow-up were compared between patients in the CCR group and creatinine increased $>50 \%$ group. Results showed that time-averaged blood pressure and time-averaged proteinuria (TA-P) were significantly different between the two groups $(P<0.001)$ as shown in Table 7. Univariate COX regression suggested that the timeaveraged mean arterial pressure (TA-MAP), diastolic pressure (TA-DBP), and time-averaged proteinuria (TA-P) were correlated with creatinine increased by greater than $50 \%$. However, multivariate COX regression suggested that only TA-P was an independent risk factor of creatinine increased by greater than $50 \%$ (Table 8 ). 


\section{Kidney Blood Pressure Research}

Table 5. Baseline characteristic to predict creatinine increased $>50 \%$. HR: Hazard Ratio

\begin{tabular}{|c|c|c|c|c|c|c|}
\hline \multirow[t]{2}{*}{ Characteristics } & \multicolumn{3}{|c|}{ univariate COX } & \multicolumn{3}{|c|}{ multivariate COX } \\
\hline & HR & $95 \% \mathrm{CI}$ & $P$ & HR & $95 \% \mathrm{CI}$ & $P$ \\
\hline Sex (male vs female) & 0.32 & $(0.17-0.59)$ & 0.065 & 0.35 & NS & \\
\hline Age (per decade.) & 1.66 & $(1.14-2.42)$ & 0.009 & 1.74 & $(1.25-2.42)$ & 0.001 \\
\hline Hypertension(yes vs no) & 1.53 & $(0.75-3.14)$ & 0.241 & & NS & \\
\hline CKD I vs CKD II & 0.86 & $(0.41-1.78)$ & 0.066 & & NS & \\
\hline Proteinuria $>0.5 \mathrm{~g} / \mathrm{d}$ & 3.31 & $(1.07-12.65)$ & 0.039 & 2.43 & $(1.36-4.36)$ & 0.003 \\
\hline Cholesterol (mmol/L) & 1.49 & $(0.93-1.51)$ & 0.161 & & NS & \\
\hline Triglyceride (mmol/L) & 0.75 & $(0.60-1.49)$ & 0.826 & & NS & \\
\hline ACEI/ARB (yes vs no) & 0.91 & $(0.41-2.02)$ & 0.808 & & NS & \\
\hline Steroids & 1.42 & $(0.66-3.03)$ & 0.379 & & NS & \\
\hline Oxford classification & & & & & NS & \\
\hline \multicolumn{7}{|l|}{ M (M1 vs M0) } \\
\hline E (E1 vs E0) & 1.11 & $(0.52-2.34)$ & 0.789 & & NS & \\
\hline $\mathrm{S}$ (S1 vs S0) & 0.72 & $(0.1-5.33)$ & 0.752 & & NS & \\
\hline$(\mathrm{T} 1+\mathrm{T} 2)$ vs $\mathrm{T} 0$ & 0.80 & (0.99-1.67) & 0.044 & & NS & \\
\hline $\mathrm{C} 1$ vs $\mathrm{C} 0$ & 1.67 & (0.89-4.07) & 0.065 & & NS & \\
\hline
\end{tabular}

Table 6. C-index of clinical model, Oxford classification. Clinical model: age + baseline proteinuria $>0.5 \mathrm{~g} / \mathrm{d}$

\begin{tabular}{lcc}
\hline & C-index $(95 \% \mathrm{CI})$ & $\mathrm{P}($ VS Clinical model $)$ \\
\hline clinical model & $0.65(0.57-0.73)^{\mathrm{a}}$ & \\
Oxford classification & $0.58(0.50-0.66)$ & 0.012
\end{tabular}

Table 7. Differences of time-averaged clinical data between patients in CCR Group and creatinine increased $>50 \%$ Group. TA-P: time-averaged proteinuria; TA-SBP time-averaged systolic pressure; TA-DBP: timeaveraged diastolic pressure; TA-MAP: time-averaged mean arterial pressure; CCR: Complete clinical remission

\begin{tabular}{lccccc}
\hline & \multicolumn{2}{c}{ CCR $(\mathrm{n}=82)$} & \multicolumn{2}{c}{ Creatinine increased $>50 \%(\mathrm{n}=54)$} & $\mathrm{P}$ \\
\hline TA-P & 0.15 & \pm 0.07 & 0.68 & \pm 0.37 & $<0.001$ \\
TA-SBP & 115.85 & \pm 9.54 & 123.78 & \pm 11.58 & $<0.001$ \\
TA-DBP & 73.37 & \pm 6.95 & 78.39 & \pm 6.87 & $<0.001$ \\
TA-MAP & 87.54 & \pm 7.20 & 93.51 & \pm 7.91 & $<0.001$ \\
\hline
\end{tabular}

Table 8. Correlations between time averaged clinical indicators and creatinine increased $>50 \%$. TA-P: timeaveraged proteinuria; TA-SBP time-averaged systolic pressure; TA-DBP: time-averaged diastolic pressure; TA-MAP: time-averaged mean arterial pressure; HR: Hazard Ratio

\begin{tabular}{lcccccc}
\hline & \multicolumn{3}{c}{ Univariate COX } & & Multivariate COX & \\
\hline & HR & $95 \%$ CI & P & HR & $95 \%$ CI & P \\
TA-MAP & 1.07 & $(1.03-1.11)$ & 0.001 & NS & & \\
TA-SBP & 1.05 & $(0.96-1.15)$ & 0.054 & NS & & \\
TA-DBP & 1.01 & $(1.00-1.05)$ & 0.001 & NS & & \\
TA-P & 8.84 & $(4.32-18.08)$ & 0.001 & 6.82 & $(2.87-16.22)$ & $<0.001$ \\
\hline
\end{tabular}




\section{Kidney Blood Pressure Research}

\section{Discussion}

Patients with proteinuria less than $1 \mathrm{~g} / \mathrm{d}$ and eGFR not below $60 \mathrm{~mL} / \mathrm{min} / 1.73 \mathrm{~m}^{2}$ during the percutaneous renal biopsy were included in this study. We found that the level of baseline proteinuria was correlated with $\mathrm{M}$, T, and $\mathrm{S}$ lesions, whereas the level of baseline CKD was correlated with $\mathrm{T}$ lesion. This result suggest that the clinical indicators could predict pathology. For patients with proteinuria greater than $0.5 \mathrm{~g}$ and eGFR less than 90 $\mathrm{mL} / \mathrm{min} / 1.73 \mathrm{~m}^{2}$, the pathology might be severe. Therefore, these patients should timely undergo percutaneous renal biopsy for identification of the degree of pathological changes.

After the renal biopsy performed in this study, $79.8 \%$ of the patients received ACEI/ARB therapy and had an average systolic pressure of $(123.5 \pm 15.7) \mathrm{mmHg}$ and average diastolic pressure of $(79.6 \pm 11.8) \mathrm{mmHg}$. Therefore, the treatment program in this study was more standardized and closer to the KDIGO guidelines [17] than those of previous studies [8].

The role of steroids in IgA nephropathy (IgAN) is controversial. In our study, 69 patients $(13.6 \%)$ received steroids therapy, but there was no statistically difference between group 1 and group 3 (Table 4). As can be seen in Table 5, steroids could not be an influencing factor for the increase in creatinine levels by $>50 \%$. These results do not support the possibility that steroids therapy may improve the outcomes of IgAN patients with mild proteinuria. The KDIGO [18] guideline support our result, which recommended that steroids therapy should be used only in IgAN patients with proteinuria $>1 \mathrm{~g} / \mathrm{d}$, since there was no powerful evidence to support that steroids could improve outcomes of IgAN patients with mild proteinuria. The STOP-IgAN Trial [19] included 162 IgAN patients with proteinuria $>0.75 \mathrm{~g} / \mathrm{d}$. The result showed that the rate of endpoints (GFR decrease $>30 \mathrm{ml} / \mathrm{min}$ per $1.73 \mathrm{~m}^{2}$, Onset of ESRD, absolute GFR changes at month 36) did not differ between patients receiving corticosteroid monotherapy and supportive care. However, In patients with proteinuria $>1 \mathrm{~g} / \mathrm{d}$, TESTING trial [20] showed that compare with placebo, methylprednisolone could decrease rate of endpoints(40\% eGFR decrease, ESRD) and increase rate of adverse events( infection). Therefore, in patients with mild proteinuria, whether steroids be used or not should be carefully considered.

No case progressed to ESRD, and 54 cases showed an increase of $50 \%$ or greater in the levels of creatinine; urinary protein of $\geq 1 \mathrm{~g} / \mathrm{d}$ was persistently present in 45 cases (8.8\%). The cumulative proportion of creatinine increased by $>50 \%$ as determined through the lifetable analysis, and the values predicted in 10,15 , and 20 years were $15 \%, 21 \%$, and $22 \%$, respectively. Gutiérrez, et al. [8] reported that during a follow-up with a median value of 108 months in a study with 141 Caucasians, the IgAN patients with mild proteinuria showed good prognosis. Their serum creatinine increased by $>50 \%$ in five patients $(3.5 \%)$; the pathological changes were mild, tubulointerstitial injury was rare, and progression to ESRD was not observed. This discrepancy was attributed mainly to the inclusion criteria (baseline proteinuria $<0.5 \mathrm{~g} / \mathrm{d}$ ), the small sample size, or the interracial differences. An earlier gene study revealed that the differences between races influence the susceptibility $[21,22]$ to and progression of IgAN [23-26]. Barbour SJ, et al. [27] analyzed the data of a cohort of 202 IgAN patients of self-reported Pacific-Asian origin and 467 of other origin obtained from the Toronto GN Registry (Toronto, Ontario, Canada) that were followed up for a median of 46.4 months. Their results showed that the individuals of Pacific-Asian origin exhibited a higher risk of eGFR decline, which indicated the racial origin should be considered in risk evaluation.

Age is another important factor for patient outcome. Many literature sources suggest that age is also a prognostic factor, and old age is correlated with poor prognosis [28, 29]. A previous study compared patients of different ages ( $\geq 50$ and $<50$ years old) and found a higher incidence of arterial intimal thickening in the elder group, but no differences in the degree of other pathological changes; the follow-up for 41 months showed no difference in survival [30]. 


\section{Kidney Blood Pressure Research}

Proteinuria has always been an important prognostic factor for patients with IgAN. In this study, proteinuria in the patients was significantly lower in the CCR group than in the group with the increase in creatinine by $>50 \%$. Multivariate regression showed that a baseline proteinuria greater than $0.5 \mathrm{~g} / \mathrm{d}$ was an independent influencing factor for the increase in creatinine by more than $50 \%$. This finding indicates that the increase in the baseline proteinuria might worsen patients' prognosis. The mean proteinuria per unit of time reflected the long-term control of patients on proteinuria during the follow-up, and this measurement was significantly correlated with the adverse endpoint events. The HR value significantly increased with the rise in TA-P, indicating that the patients in this study had minor proteinuria, which, however, could not be ignored. The risk of progression of renal function would be higher if intervention was not proactively taken.

Pathology has been regarded as an important influencing factor for the prognosis of IgAN. Reportedly [7, 31-34], according to the Oxford classification, the M, E, S, T, and C lesions are partially related to the prognosis. Barbour SJ [31] found that M/T lesions were independently associated with renal outcome. The results of Bellur SS [35] support the S score of the Oxford Classification in patients without immunosuppression. Trimarchi, et al. [36] reviewed the current classification parameters of the Oxford classification and put forward the revised MEST-C score. However, the results of these examinations were primarily derived from patients with proteinuria greater than $1 \mathrm{~g} / \mathrm{d}$. In this study, we established that for patients with minor proteinuria, , only the $\mathrm{T}$ lesions were correlated pathologically with the adverse endpoint events. According to the results of the multivariate regression analysis, after the clinical indicators were corrected, pathology could not be used as an independent factor to predict the endpoint events. This suggested that pathological changes do not possess higher predictive ability than clinical indicators in predicting adverse endpoint events. Other studies [31,35-38] in IgAN patients seem to have obtained different results. However, there are no conflicts with our results, because some differences, such as the inclusion criteria, stratification, and correction factors of multivariate analysis or definition of outcomes, might have led to variations in the results. Coppo R, et al. [38] analyzed 1,147 IgAN patients in the VALIGA cohort and suggested that M/S/T independently predicted renal outcome $(50 \%$ reduction in renal function and/or ESRD). However, in a subgroup of 219 patients with minimal proteinuria, no MEST score predicted renal outcome in the multivariate analysis, which supports our results. Another examination, conducted by Coppo R [37], failed to confirm that MEST scores had a predictive value in a subgroup of 174 children ( $<18$ years) in the VALIGA cohort. These results indicated that the evaluation of the Oxford classification should be stratified.

We further calculated the C-index that reflects the predictive value of the models, and found that the models based on clinical indices had a C-index that was significantly higher than that of the Oxford classification, indicating that clinical indices possessed a higher prognostic value than pathological changes. These results may be attributed to the relatively mild pathological changes in the patients with a urinary protein level lower than $1 \mathrm{~g} / \mathrm{d}$. In addition, the prompt treatment might, at least partially, have reversed the pathological changes and thus further diminished their influence. Other studies also could not verify that the MEST score had higher C-index than clinical data in predicting the renal outcome. Barbour SJ, et al. [31] calculated the C-index in 901 IgAN patients with average baseline proteinuria of $1.5 \mathrm{~g} / \mathrm{d}(0.8-2.6 \mathrm{~g} / \mathrm{d})$. There was no evidence that the C-index of the MEST score was higher than that of clinical data. Only the combination of MEST score and clinical data increased the $\mathrm{C}$-index by 0.05 .

Several limitations of this study should be noted. The data were obtained from a single institution in China. The generalizability for populations of other races might have been limited. Second, patients with higher proteinuria and more advanced pathologic findings were likely to receive more aggressive treatment. In addition, the dosage and course of steroids was individualized. The effects of the therapeutic intervention on the progression need to be confirmed in a larger number of clinical studies. Third, the follow-up of the IgA 


\section{Kidney Bloód Pressure Research}

nephropathy clinical endpoints of ESRD was relatively short. We will perform a prospective study with longer a follow-up period in the future.

\section{Conclusion}

(1) Proteinuria $>0.5 \mathrm{~g} / \mathrm{d}$ and $\mathrm{eGFR}<90 \mathrm{~mL} / \mathrm{min} / 1.73 \mathrm{~m}^{2}$ may predict more severe pathological changes; (2) With the increase in age and baseline proteinuria, the risks of adverse endpoint events increase significantly; (3) Pathology could roughly predict the adverse endpoint events but was less efficient than the clinical indicators; (4) The data collected during the follow-up period suggested that the patients should regularly check their renal function and proactively control their proteinuria.

\section{Acknowledgements}

This work was supported by grants from The Science and Technology Project of Beijing, China (1. No. D131100004713003 and 2. No. D171100002817002), the National Natural Science Foundation of China (No. 81330019), and the National Key Technology R\&D Program (2015BAI12B06).

\section{Disclosure Statement}

The authors declared that there were no conflicts of interest in either conducting the study or analyzing the results.

\section{References}

1 Alamartine E, Sabatier JC, Berthoux FC: Comparison of pathological lesions on repeated renal biopsies in 73 patients with primary IgA glomerulonephritis: value of quantitative scoring and approach to final prognosis. Clin Nephrol 1990;34:45-51.

2 Schena FP: A retrospective analysis of the natural history of primary IgA nephropathy worldwide. Am J Med 1990;89:209-215.

3 Xie J, Kiryluk K, Wang W, Wang Z, Guo S, Shen P, Ren H, Pan X, Chen X, Zhang W, Li X, Shi H, Li Y, Gharavi AG, Chen N: Predicting progression of IgA nephropathy: new clinical progression risk score. PLoS One 2012;7:e38904.

4 Wyatt RJ, Julian BA: IgA nephropathy. N Engl J Med 2013;368:2402-2414.

5 Coppo R, D’Amico G: Factors predicting progression of IgA nephropathies. J Nephrol 2005;18:503-512.

6 Berthoux F, Mohey H, Laurent B, Mariat C, Afiani A, Thibaudin L: Predicting the risk for dialysis or death in IgA nephropathy. J Am Soc Nephrol 2011;22:752-761.

-7 Lv J, Shi S, Xu D, Zhang H, Troyanov S, Cattran DC, Wang H: Evaluation of the Oxford Classification of IgA nephropathy: a systematic review and meta-analysis. Am J Kidney Dis 2013;62:891-899.

-8 Gutiérrez E, Zamora I, Ballarín JA, Arce Y, Jiménez S, Quereda C, Olea T, Martínez-Ara J, Segarra A, Bernis C, García A, Goicoechea M, de Vinuesa S G, Rojas-Rivera J, Praga M: Long-term outcomes of IgA nephropathy presenting with minimal or no proteinuria. J Am Soc Nephrol 2012;23:1753-1760.

9 Szeto CC, Lai FM, To KF, Wong TY, Chow KM, Choi PC, Lui SF, Li PK: The natural history of immunoglobulin a nephropathy among patients with hematuria and minimal proteinuria. Am J Med 2001;110:434-437.

10 Lai FM, Szeto CC, Choi PC, Li PK, Chan AW, Tang NL, Lui SF, Wang AY, To KF: Characterization of early IgA nephropathy. Am J Kidney Dis 2000;36:703-708.

11 Shen P, He L, Huang D: Clinical course and prognostic factors of clinical early IgA nephropathy. Neth J Med 2008;66:242-247. 


\section{Kidney \\ Blood Pressure Research}

Chen et al.: IgA Nephropathy Patients with Mild Proteinuria

12 Erdogmus S, Kiremitci S, Celebi ZK, Akturk S, Duman N, Ates K, Erturk S, Nergizoglu G, Kutlay S, Sengul S, Ensari A, Keven K: Non-Diabetic Kidney Disease in Type 2 Diabetic Patients: Prevalence, Clinical Predictors and Outcomes. Kidney Blood Press Res 2017;42:886-893.

13 Stevens LA, Claybon MA, Schmid CH, Chen J, Horio M, Imai E, Nelson RG, Van Deventer M, Wang HY, Zuo L, Zhang YL, Levey AS: Evaluation of the Chronic Kidney Disease Epidemiology Collaboration equation for estimating the glomerular filtration rate in multiple ethnicities. Kidney Int 2011;79:555-562.

14 Roberts IS, Cook HT, Troyanov S, Alpers CE, Amore A, Barratt J, Berthoux F, Bonsib S, Bruijn JA, Cattran DC, Coppo R, D’Agati V, D’Amico G, Emancipator S, Emma F, Feehally J, Ferrario F, Fervenza FC, Florquin S, Fogo A, et al.: The Oxford classification of IgA nephropathy: pathology definitions, correlations, and reproducibility. Kidney Int 2009;76:546-556.

15 Chang WX, Arai S, Tamura Y, Kumagai T, Ota T, Shibata S, Fujigaki Y, Shen ZY, Uchida S: Time-dependent risk factors associated with the decline of estimated GFR in CKD patients. Clin Exp Nephrol 2016;20:58-70.

16 Caliskan Y, Ozluk Y, Celik D, Oztop N, Aksoy A, Ucar AS, Yazici H, Kilicaslan I, Sever MS: The Clinical Significance of Uric Acid and Complement Activation in the Progression of IgA Nephropathy. Kidney Blood Press Res 2016;41:148-157.

17 Floege J, Feehally J: Treatment of IgA nephropathy and Henoch-Schönlein nephritis. Nat Rev Nephrol 2013;9:320-327.

18 Andrassy KM: Comments on 'KDIGO 2012 Clinical Practice Guideline for the Evaluation and Management of Chronic Kidney Disease'. Kidney Int 2013;84:622-623.

19 Rauen T, Fitzner C, Eitner F, Sommerer C, Zeier M, Otte B, Panzer U, Peters H, Benck U, Mertens PR, Kuhlmann U, Witzke O, Gross O, Vielhauer V, JFE M, Hilgers RD, Floege J: Effects of Two Immunosuppressive Treatment Protocols for IgA Nephropathy. J Am Soc Nephrol 2018;29:317-325.

20 O'Shaughnessy MM, Lafayette RA: Corticosteroids for IgA Nephropathy: TESTING for Benefit, Discovering Harm. JAMA 2017;318:429-431.

21 Gao J, Wang M, Wei L, Niu D, Wei J, Ou Y, Jin T, Yu Q, Liu X, Tian T, Dai C, Fu R, Wang L: The Endothelial Nitric Oxide Synthase Gene Polymorphism is Associated with the Susceptibility to Immunoglobulin a Nephropathy in Chinese Population. Kidney Blood Press Res 2017;42:608-616.

22 Gao J, Wei L, Fu R, Wei J, Niu D, Wang L, Ge H, Yu Q, Wang M, Liu X, Zhang W: Association of Interleukin-10 Polymorphisms (rs1800872, rs1800871, and rs1800896) with Predisposition to IgA Nephropathy in a Chinese Han Population: A Case-Control Study. Kidney Blood Press Res 2017;42:89-98.

23 Saka S, Hirawa N, Oka A, Yatsu K, Hirukawa T, Yamamoto R, Matsusaka T, Imai E, Narita I, Endoh M, Ichikawa I, Umemura S, Inoko H: Genome-wide association study of IgA nephropathy using 23465 microsatellite markers in a Japanese population. J Hum Genet 2015;60:573-580.

24 Zhu L, Zhai YL, Wang FM, Hou P, Lv JC, Xu DM, Shi SF, Liu LJ, Yu F, Zhao MH, Novak J, Gharavi AG, Zhang H: Variants in Complement Factor H and Complement Factor H-Related Protein Genes, CFHR3 and CFHR1, Affect Complement Activation in IgA Nephropathy. J Am Soc Nephrol 2015;26:1195-1204.

25 Feehally J, Farrall M, Boland A, Gale DP, Gut I, Heath S, Kumar A, Peden JF, Maxwell PH, Morris DL, Padmanabhan S, Vyse TJ, Zawadzka A, Rees AJ, Lathrop M, Ratcliffe PJ: HLA has strongest association with IgA nephropathy in genome-wide analysis. J Am Soc Nephrol 2010;21:1791-1797.

-26 Gao J, Wei L, Liu X, Wang L, Niu D, Jin T, Yao G, Wang M, Yu Q, Fu R: Association Between IFN- $\gamma$ Gene Polymorphisms and IgA Nephropathy in a Chinese Han Population. Kidney Blood Press Res 2017;42:136144.

27 Barbour SJ, Cattran DC, Kim SJ, Levin A, Wald R, Hladunewich MA, Reich HN: Individuals of Pacific Asian origin with IgA nephropathy have an increased risk of progression to end-stage renal disease. Kidney Int 2013;84:1017-1024.

28 Knoop T, Vågane AM, Vikse BE, Svarstad E, Magnúsdóttir BT, Leh S, Varberg RA, Bjørneklett R: Addition of eGFR and Age Improves the Prognostic Absolute Renal Risk-Model in 1, 134 Norwegian Patients with IgA Nephropathy. Am J Nephrol 2015;41:210-219.

29 Oshima Y, Moriyama T, Itabashi M, Takei T, Nitta K: Characteristics of IgA nephropathy in advanced-age patients. Int Urol Nephrol 2015;47:137-145.

-30 Frimat L, Hestin D, Aymard B, Mayeux D, Renoult E, Kessler M: IgA nephropathy in patients over 50 years of age: a multicentre, prospective study. Nephrol Dial Transplant 1996;11:1043-1047. 


\section{Kidney \\ Blood Pressure Research}

-31 Barbour SJ, Espino-Hernandez G, Reich HN, Coppo R, Roberts IS, Feehally J, Herzenberg AM, Cattran DC: The MEST score provides earlier risk prediction in lgA nephropathy. Kidney Int 2016;89:167-175.

-32 Ştefan G, Ismail G, Stancu S, Zugravu A, Andronesi A, Mandache E, Mircescu G: Validation study of Oxford Classification of IgA Nephropathy: the significance of extracapillary hypercellularity and mesangial IgG immunostaining. Pathol Int 2016;66:453-459.

-33 Haas M, Verhave JC, Liu ZH, Alpers CE, Barratt J, Becker JU, Cattran D, Cook HT, Coppo R, Feehally J, Pani A, Perkowska-Ptasinska A, Roberts IS, Soares MF, Trimarchi H, Wang S, Yuzawa Y, Zhang H, Troyanov S, Katafuchi R: A Multicenter Study of the Predictive Value of Crescents in IgA Nephropathy. J Am Soc Nephrol 2017;28:691-701.

-34 Zhang J, Ren P, Wang Y, Feng S, Wang C, Shen X, Weng C, Lang X, Chen Z, Jiang H, Chen J: Serum Matrix Metalloproteinase-7 Level is Associated with Fibrosis and Renal Survival in Patients with IgA Nephropathy. Kidney Blood Press Res 2017;42:541-552.

35 Bellur SS, Lepeytre F, Vorobyeva O, Troyanov S, Cook HT, Roberts IS: Evidence from the Oxford Classification cohort supports the clinical value of subclassification of focal segmental glomerulosclerosis in IgA nephropathy. Kidney Int 2017;91:235-243.

-36 Trimarchi H, Barratt J, Cattran DC, Cook HT, Coppo R, Haas M, Liu ZH, Roberts IS, Yuzawa Y, Zhang H, Feehally J: Oxford Classification of IgA nephropathy 2016: an update from the IgA Nephropathy Classification Working Group. Kidney Int 2017;91:1014-1021.

-37 Coppo R, Lofaro D, Camilla RR, Bellur S, Cattran D, Cook HT, Roberts IS, Peruzzi L, Amore A, Emma F, Fuiano L, Berg U, Topaloglu R, Bilginer Y, Gesualdo L, Polci R, Mizerska-Wasiak M, Caliskan Y, Lundberg S, Cancarini $\mathrm{G}$, et al.: Risk factors for progression in children and young adults with IgA nephropathy: an analysis of 261 cases from the VALIGA European cohort. Pediatr Nephrol 2017;32:139-150.

-38 Coppo R, Troyanov S, Bellur S, Cattran D, Cook HT, Feehally J, Roberts IS, Morando L, Camilla R, Tesar V, Lunberg S, Gesualdo L, Emma F, Rollino C, Amore A, Praga M, Feriozzi S, Segoloni G, Pani A, Cancarini G, et al.: Validation of the Oxford classification of IgA nephropathy in cohorts with different presentations and treatments. Kidney Int 2014;86:828-836. 